\title{
Buluba Leprosy Hospital, Uganda: a review of admissions, 1981-84
}

\author{
H J KAWUMA \\ Buluba Leprosy Hospital, c/o Nsambya Hospital, PO Box 7146, \\ Kampala, Uganda
}

\section{Accepted for publication 8 February 1987}

\begin{abstract}
Summary The current functions of Buluba Leprosy Hospital are outlined. An analysis of 2416 conditions necessitating the admission to hospital of 1944 leprosy patients registered for treatment in the control area over a period of 4 years, 19811984, has been made and the relative frequency of the reasons for admission indicated. It is shown that over $40 \%$ of the work load of the hospital, for treatment, involved conditions not due to leprosy and could have been undertaken by the general health services of the area. The possibility of decreasing the number of admissions by improving the efficiency of the field projects is discussed. The indications are that the introduction of the WHO recommended multidrug regimens will not significantly reduce the number of admissions to hospital, other circumstances remaining unchanged.

In the future, the main functions of the hospital should be to treat the complications of leprosy and to provide adequate and appropriate leprosy training for the staff of the general hospitals and other health units. The need to elicit the help of various specialists in the fields of medicine and surgery is emphasized. It is suggested that in the longer term it might be possible to transfer more of the responsibilities for the care of leprosy patients to the general health staff, but that this transfer should be gradual and take into account implications possibly detrimental to the care of the patients.
\end{abstract}

\section{Introduction}

Since 1981, Buluba Leprosy Hospital has been the referral hospital for leprosy control schemes covering the Districts of Iganga, Jinja and Kamuli (the SouthEastern Region), Mukono, Kampala, Entebbe, Mubende and Luwero (the Central Region) and Mpigi, Masaka and Rakai (the Southern Region) of Uganda, see Figure 1.

The total numbers of leprosy patients treated in the schemes ranged from 5937 in 1981 to 4362 at the end of 1984 . It has been estimated ${ }^{2}$ that at 31 December 1983 there were 23,000 patients under treatment in the whole country and 


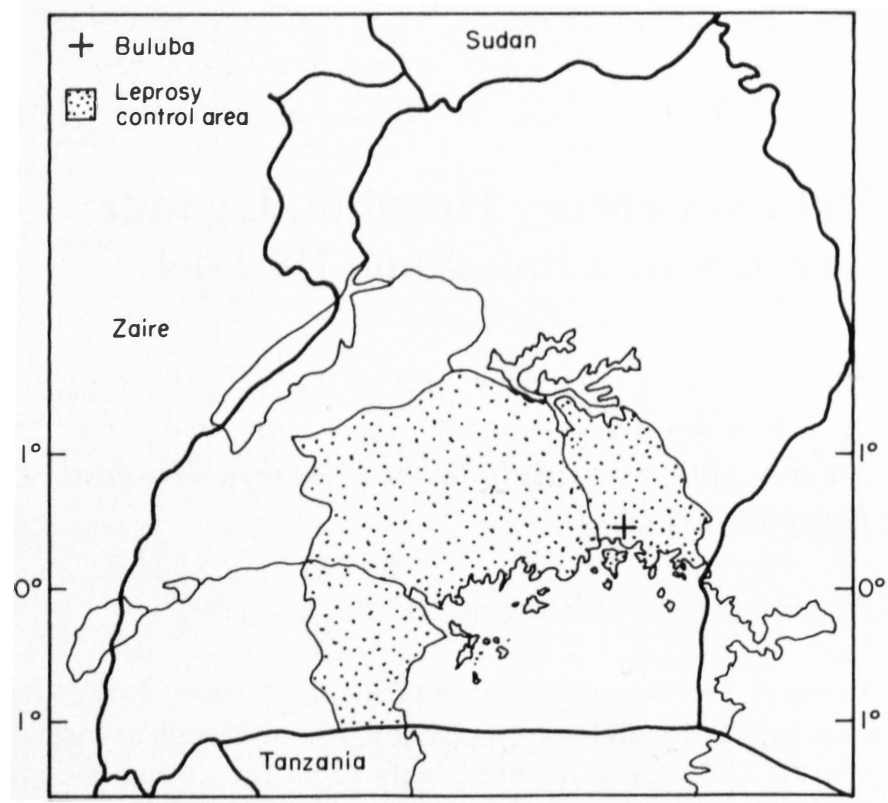

Figure 1. Map of Uganda showing location of Buluba Leprosy Hospital and the leprosy control area covered by the hospital.

accordingly that these schemes covered about $19 \%$ of all the patients in Uganda at that time.

As at 31 December 1984, about $15 \%$ of the patients in the control area belonged to the multibacillary types of leprosy, i.e. lepromatous (LL), borderline lepromatous (BL) and mid-borderline (BB) according to the Ridley-Jopling classification ${ }^{5}$.

Outpatient treatment in the control area is provided through a special leprosy service in the South-Eastern Region and in a partially integrated service in the Central and Southern Regions. In all areas, the paramedical personnel responsible were trained to recognize complications of the disease and to refer those needing hospital treatment.

Buluba Leprosy Centre also runs a training programme in leprosy for medical undergraduates from the Medical School in Kampala, and for other medical training institutions, e.g. Nursing Schools, situated within the control area.

\section{Aims of the study}

This study was undertaken: 1 , to assess how much of the current work of the hospital could be done, in a general hospital; 2 , to evaluate the performance of the field work projects in the light of the conditions for which patients were admitted to hospital; 3 , to try to predict the likely change in the role of the hospital 
following the introduction (in the control area) of the World Health Organisation (WHO) recommended multiple drug therapy (MDT) regimens ${ }^{7}$; and 4 , to determine what could be the future function of a special leprosy hospital in the control area.

\section{Materials and methods}

The hospital records of the 1944 leprosy patients admitted to Buluba during the 4year period 1981-1984 were analysed. The indications for admission were grouped for each year following the format of the Annual Leprosy Returns of the Uganda Ministry of Health.

\section{Results}

The results of the analysis of these indications are shown in Table 1. In some cases patients were admitted for 2 or more of the listed indications and therefore the actual number of patients is lower than the figures given in Table 1. All conditions for which treatment and care were provided are included. It is of note that, taking the 4-year period as a whole, conditions not due to leprosy comprise some $41 \%$ of the total.

Table 2 shows that the number of patients hospitalized during each of the 4 years is between 8 and $10 \%$ of those under treatment in the control area at the end of each year. This proportion would, of course, be lower if the denominator were taken as the total receiving treatment during the year, including those released from treatment, defaulters, transfers and those who had died.

Table 1. Analysis of the indications for admission of leprosy patients to Buluba Leprosy Hospital between January 1981 and December 1984

\begin{tabular}{|c|c|c|c|c|c|c|}
\hline Indication & 1981 & 1982 & 1983 & 1984 & Total & $\%$ \\
\hline I Reactions & 154 & 52 & 80 & 60 & 346 & $14 \cdot 3$ \\
\hline 2 Trophic ulcer & 97 & 123 & 109 & 53 & 382 & $15 \cdot 8$ \\
\hline 3 Eye complications of leprosy & 7 & 6 & 9 & 5 & 27 & $1 \cdot 1$ \\
\hline 4 Surgery & 11 & 59 & 97 & 65 & 232 & $9 \cdot 6$ \\
\hline 5 Drug resistance & 3 & 5 & 7 & 5 & 20 & $0 \cdot 8$ \\
\hline 6 Combined therapy & 44 & 48 & 53 & 61 & 206 & $8 \cdot 5$ \\
\hline 7 Orthopaedic appliances & 21 & 14 & 16 & 38 & 89 & $3 \cdot 7$ \\
\hline 8 Relapses & 10 & 8 & 5 & 16 & 39 & $1 \cdot 6$ \\
\hline 9 Other reasons, e.g. for diagnosis & 18 & 13 & 16 & 34 & 81 & $3 \cdot 4$ \\
\hline 10 Conditions not due to leprosy & 201 & 254 & 180 & 359 & 994 & $41 \cdot 1$ \\
\hline Total & 566 & 582 & 572 & 696 & 2416 & $99 \cdot 9$ \\
\hline
\end{tabular}


Table 2. Proportion of registered leprosy patients who were admitted to Buluba Hospital during the year

\begin{tabular}{|c|c|c|c|c|c|}
\hline & 1981 & 1982 & 1983 & 1984 & \\
\hline Number registered on 31 st December & 5837 & 5626 & 5130 & 4362 & \\
\hline Number hospitalized during year & $\begin{array}{c}516 \\
(8.8 \%)\end{array}$ & $\begin{array}{c}503 \\
(8.9 \%)\end{array}$ & $\begin{array}{c}488 \\
(9 \cdot 5 \%)\end{array}$ & $\begin{array}{c}437 \\
(10 \%)\end{array}$ & (total 1944) \\
\hline
\end{tabular}

\section{Discussion}

According to the World Health Organisation, the role of sanatoria should be limited to the treatment of cases with acute lepra reaction or other complications and to serving as centres for research and training. ${ }^{6}$

In Table 2, an upward trend is observed in the percentage of patients admitted (from $8.8 \%$ in 1981 to $10.0 \%$ in 1984) and it is thought that this may be due to a proportionately greater decrease in the number registered for treatment than in the number with complications requiring admission.

Table 1 shows that the most frequent indication for admission, in $41.1 \%$ of cases, was for treatment of conditions not due to leprosy. A further $9.6 \%$ (232 patients) underwent surgery, in which more than half of the operations could have been performed in any general hospital. It is clear, therefore, that well over $40 \%$ of the work load on hospitalized patients could have been shared with the other general hospitals-at least 10-within the control area. This did not happen. It is not known how many leprosy patients were treated in these general hospitals but the data available to us suggests that they could have taken on more than they did. WHO does not recommend the development of special surgical units in leprosaria; ${ }^{6}$ rather it would prefer referral of patients needing surgery to general hospitals where qualified staff are available.

Even if admissions for conditions not due to leprosy could be shifted to other hospitals, it appears that for the time being a special leprosy hospital would be necessary for the management of complications of leprosy.

Leprosy reactions, ranking in Table 2 as the third most frequent indication for admission, are expected complications of leprosy and the problem they posed during the period under review will be the subject of another paper. ${ }^{3}$ It is known that failure to recognize reactions early and failure to manage them properly starts off a sequence of further complications, especially deformities resulting from nerve damage. Deformities contribute to a considerable extent to the rejection of leprosy patients in general health units. 
The frequency of admissions for the treatment of trophic ulcers (15.8\% of all) suggests either that patients were diagnosed late, with irreversible nerve damage and its sequelae, or that those who were diagnosed early did not receive the appropriate care to prevent this complication.

Part of this appropriate care is the early recognition and proper management of reactions, particularly those associated with neuritis. The reduction in the number of admissions for the treatment of trophic ulcers will depend to a large extent on early case finding and proper case holding under field conditions. This has been suggested as the surest and cheapest method of preventing physical disability.

According to the WHO recommended proposals, it should be possible to provide partly supervised multidrug therapy for all types of leprosy patients even under field conditions. ${ }^{7}$ It is hoped that the short-term multidrug regimen will result in a rapid decrease in the number of patients requiring anti-leprosy treatment, the case load. If this happened, it would lead to a decrease of no more than $10 \%$ of the work load of the hospital wards, because there would not be proportionately fewer reactions, eye complications or trophic ulcers.

The study also suggests that the personnel manning the hospital are attempting to play 'Jack of all trades', and this has negative implications for the quality of service provided to the patients. It leaves too little time and resources for fulfilling the two main roles of a leprosy hospital stated at the opening of this discussion. It has been suggested by Jopling ${ }^{1}$ that a central leprosy hospital where patients can be investigated and treated and where leprosy can be taught should, ideally, be placed close to a large medical centre so that the leprosy unit can call upon the specialist services available. This possibility has not yet been adequately explored, although it was in 1970 that Lomholt ${ }^{4}$ observed that in order to meet the challenges of this disease dermatologists and leprologists needed help from other specialists, notably ophthalmologists and orthopaedic surgeons. To these I would like to add physicians!

The conclusion to be drawn from this study is that a leprosy hospital will be required in our control area at least for some years to come. Its main functions will be: 1 , to care for patients with complications of leprosy; and 2 , to train medical and auxiliary personnel in the area to play their part in caring for leprosy patients. Then, hopefully, it will gradually become easier to admit these patients to general hospitals for the treatment of intercurrent medical and surgical problems, thus incidentally providing an opportunity for the staff to learn about leprosy. Such a future may well encourage Buluba to take on new objectives, without dangerous implications for the leprosy patients. Until these dreams come true, it is suggested that those responsible for planning for Buluba should heed the WHO warning against 'relegation of leprosy control to ill-prepared general health staff without adequate consideration of the implications of such a rapid transfer of responsibility' ${ }^{6}$ 


\title{
Acknowledgments
}

I wish to express my heartfelt thanks to Mr John Waibi for assisting me in the collection of data. I am also very grateful to Dr Wanda Blenska, Consultant Leprologist, for all her help and guidance. I am indebted to Miss Helen Apiyo Edunyu for secretarial assistance.

\section{References}

1 Jopling WH. Handhook of Leprosy, 2nd ed. William Heinemann Medical Books Ltd, 1978; 78.

${ }^{2}$ Kawuma HJS. Leprosy in Uganda: a review of the present situation. Unpublished paper written for WHO Working Group on implementation of MDT in English-speaking African countrics, 1984.

${ }^{3}$ Kawuma, HJS. A review of admission of leprosy patients for treatment of reversal reaction, during a five year period (1980-1984). In Preparation.

${ }^{4}$ Lomholt G. Dermatology and Venereology-New' Disciplines. Makerere Med J, 1970; 14: 15.

5 Ridley DS, Jopling WH. Classification of Leprosy according to immunity. A five group system. Int J Lepr, 1966; 34: 255.

6 WHO. A Guide to Leprosy Control. WHO: Geneva, 1980.

7 WHO. Chemotherapy of leprosy for control programmes. Technical Report Serics No. 675. WHO: Geneva, 1982.

\section{NEWS AND NOTES}

\begin{abstract}
A lazar house at Bodmin, Cornwall
We are grateful to Dr C R Grainger of Truro, Cornwall for the following historical note: There were a large number of lazar houses in Cornwall and there are records of one of these in Bodmin, dating from the thirteenth century. By 1382 the hospital was surrounded by ample pasturage for a herd of cows and there was a mill, a number of houses, a prison and dungeon as well as a chapel consecrated in that year by the Bishop of Exeter. The religious nature of the hospital was important and indulgencies were granted in 1395 and again in 1455. The institution was not affected by the dissolution of the monasteries by Henry VIII whilst a commission appointed by Edward VI in 1548 to survey the institutions despoiled by Henry VIII certified the charitable nature of St Lawrence Hospital and it continued its work without hindrance. A Charter of Incorporation was granted by Queen Elizabeth I in 1582 which was intended to maintain the number of patients with leprosy at forty by allowing a sufferer to fill any vacancy that occurred in the hospital.

The institution benefited during the reign of James I. The hospital was granted the right to hold a weekly market on Wednesdays, an annual fair to be held on St Luke's Day and a Pie Powder Court. The number of cases of leprosy declined so that by the beginning of the nineteenth century there were less than 40 cases. Because of this decline legal proceedings were instituted to divert the resources from the care of patients with leprosy to the support of the Royal Cornwall Infirmary. This change took place in August 1810 on the remarkable condition that any leprous person should be admitted to the infirmary in preference to other cases and provided with proper treatment and accommodation.

No trace now remains of the lazar house and the only tangible evidence is the seal of St Lawrence and an inscribed slab of stone. The other existing relic is a stone with the inscription: 'Richard Carter of Saynte Columbe merchante of his laste wylle and testamente in Anno Dni 1582 did geve ten pownde for the assurance of twentie shyllynges yerelye to be payed unto us poer lepers of the Hospytall and to oure successors for ever which ten pownde by the consent of hys executor we have employed towards the makyng of thys house in Anno 1588 whose charitable and rare example in oure tyme God grante mani to followe hereafter.'
\end{abstract}

